\title{
Effects and time-kill assessment of amoxicillin used in combination with chloramphenicol against bacteria of clinical importance
}

\author{
Olufunmiso O. Olajuyigbe ${ }^{1,2 \bowtie}$, Roger M. Coopoosamy ${ }^{1}$ and Anthony J. Afolayan² \\ 'Department of Nature Conservation, Mangosuthu University of Technology, Durban, KwaZulu-Natal, South Africa; 2Medicinal Plants and Eco- \\ nomic Development Research Centre, University of Fort Hare, Alice, 5700, South Africa
}

\begin{abstract}
With the emergence of multidrug-resistant organisms in an era when drug development faces challenges causing pharmaceutical companies to curtail or abandon research on anti-infective agents, the use of combined existing antimicrobial agents may be an alternative. This study evaluated the effects of combining amoxicillin and chloramphenicol, to which many bacteria have become resistant, in vitro against Gram positive and Gram negative bacteria by agar diffusion, checkerboard and time-kill assays. The test isolates were susceptible to amoxicillin with minimum inhibitory concentrations (MICs) ranging between 0.448 and $500 \mu \mathrm{g} / \mathrm{ml}$ and between 1.953 and $31.25 \mu \mathrm{g} / \mathrm{ml}$ for chloramphenicol. Upon combining these agents, there was a drastic reduction in their MICs indicating an increased antibacterial activity that showed synergistic interaction against all the bacteria. At the highest concentrations, the inhibition zones ranges were $20.33-38.33 \pm 0.58 \mu \mathrm{g} / \mathrm{ml}$ for amoxicillin, $27.67-37.67 \pm 0.58 \mu \mathrm{g} / \mathrm{ml}$ for chloramphenicol and $31.67-39.33 \pm 0.58 \mu \mathrm{g} / \mathrm{ml}$ for the combined agents. The fractional inhibitory concentration indices (FICIs) showed synergy ranging from 0.129 to 0.312 while $\mathrm{FICls}$ for additive interaction were between 0.688 and 1.0. There was no antagonistic interaction. At the $1 / 2 \mathrm{MICs}$ of the combined antibiotics, all the tested bacteria, except for Klebsiella pneumoniae ATCC 4352, Proteus vulgaris CSIR 0030 and Enterococcus cloacae ATCC 13047 were eliminated before $24 \mathrm{~h}$. At the MICs, all the tested bacteria were eliminated except Enterococcus cloacae ATCC 13047 which was almost totally eliminated. Post-antibiotic assessment after $48 \mathrm{~h}$ showed that all the cultures were sterile except for that of Enterococcus cloacae ATCC 13047. The lack of antagonism between these antibacterial agents in checkerboard and time-kill assays suggested that combining amoxicillin with chloramphenicol can provide an improved therapy in comparison to the use of each antibiotic individually. The study indicates the potential beneficial value of combining amoxicillin and chloramphenicol in the treatment of microbial infections in clinical settings.
\end{abstract}

Keywords: drug-drug interactions; fractional inhibitory concentrations; multidrug resistance; time-kill assessment

Received: 31 December, 2016; revised: 13 February, 2017; accepted: 11 August, 2017; available on-line: 30 November, 2017

e-mail: funmijuyigbe12@yahoo.com

Abbreviations: FICls, fractional inhibitory concentration indices; MDR, multidrug resistance; MICs, minimum inhibitory concentrations

\section{INTRODUCTION}

In the late twentieth century the availability and success of antibiotics and vaccinations resulted in a confidence that technology and modern medicine would be victorious against infectious diseases. During this early period of the antibiotic usage bacterial infections were considered tamed as potentially lethal infections were being cured with antibiotics. However, while the introduction of antimicrobial agents was accompanied by negative rather than positive impact on the patients, the number of individuals to be treated with antibiotics increased with enhanced pathogenicity and invasiveness. The widespread use of antibiotic, therefore, resulted in the emergence of outbreaks and epidemics of antibiotic-resistant pathogens including multidrug resistant strains (Normak \& Normak, 2002). Today, resistant pathogens, an underappreciated threat to public health throughout the globe (Zhang et al., 2006), are rapidly growing problems leading to an urgent need for novel antimicrobial agents (Kumar \& Schweizer, 2005; Edgar et al., 2012).

Although there is a continued effort into seeking new therapies in response to the consequences of the pressure on the widespread use of antibiotics or problems associated with increasing drug resistance (Cameron et al., 2004), bacteria have, also, continued to develop different resistance mechanisms to virtually all antibiotics in general clinical practices (Clatworthy et al., 2007). These resistance mechanisms may include altered penicillinbinding proteins, presence of various $\beta$-lactamases and loss of porins (Bou \& Martinez-Beltran, 2000). While active efflux and enzymatic inactivation are the mechanisms responsible for resistance to aminoglycosides (Smith et al., 2007), the most common mechanisms of resistance to chloramphenicol are decreased outer membrane permeability (Burns et al., 1989), enzymatic inactivation by acetylation essentially by acetyltransferase or by chloramphenicol phosphotransferases (Schwartz et al., 2004; Aakra et al., 2010), target site modulation (Montero et al., 2007) and presence of efflux pump (Daniels \& Ramos, 2009). To overcome various resistance mechanisms and dissemination of antibiotic resistance genes, exploring the possible synergy between conventional antibiotics becomes necessary. This study, therefore, aimed at investigating the combinatory effects and time-kill assessment of amoxicillin and chloramphenicol against bacteria of clinical importance. These antibiotics have long been used for the treatment of enteric fever. However, most enteric organisms including Salmonella typhi causing typhoid fever have become highly resistant to them (Kabra, 2000; Das \& Bhattacharya, 2000). 


\section{MATERIALS AND METHODS}

Bacterial culture and preparation of antibiotic solutions. The bacteria used in this study included Shigella sonnei ATCC 29930, Salmonella typhi ATCC 13311, Staphylococcus aureus $\mathrm{OK}_{2 \mathrm{a}}$, Acinetobacter calcoacenticus UP, Enterococcus cloacae ATCC 13047, Proteus vulgaris CSIR 0030, Pseudomonas aeruginosa ATCC 19582, Bacillus cereus ATCC 10702, Klebsiella pneumoniae ATCC 4352 and Staphylococcus aureus ATCC 6538. Antibiotic powders of Amoxicillin (Duchefa) and Chloramphenicol (Duchefa) were used. Stock antibiotic solutions were prepared and dilutions made according to the manufacturer's recommendations.

Antibiotic susceptibility testing-Agar diffusion method. Each bacterial strain's colony suspension was matched with $0.5 \mathrm{McF}$ arland standards to give a resultant concentration of $1.5 \times 10^{7} \mathrm{cfu} / \mathrm{ml}$. The antibiotic susceptibility was determined by swabbing the Mueller-Hinton agar (MHA) (Oxoids UK) plates with the adjusted bacterial strains. Agar wells were made with heat sterilized 6 $\mathrm{mm}$ cork borer before being filled with $100 \mu \mathrm{l}$ of different solutions $(62.5 \mu \mathrm{g} / \mathrm{ml}, 125 \mu \mathrm{g} / \mathrm{ml}$ and $250 \mu \mathrm{g} / \mathrm{ml})$ of each of the antibiotics. These concentration ranges were chosen to cover the maximum serum therapeutic range that could be reached in vivo when $100 \mu \mathrm{l}$ of each antibiotic was dispensed. Different solutions containing the same concentrations of amoxicillin and chloramphenicol were prepared and used to determine the effect of combining the antibiotics with care taken to prevent spillage of the solutions onto the agar surface. The plates, in triplicate, were allowed to stand for $1 \mathrm{~h}$ before being incubated at $37^{\circ} \mathrm{C}$ for $24 \mathrm{~h}$. After incubation, the diameter of the inhibition zones produced by each antibiotic alone and their combinations were measured with a transparent ruler. Synergism was stated when inhibition zones of combination treatment were at least $0.5 \mathrm{~mm}$ larger than those produced by the individual antibiotics.

Determination of minimal inhibitory concentration (MIC). To determine the MICs of each antibiotic, $100 \mu \mathrm{l}$ of each bacterium was added to different concentrations $(0.0019-500 \mu \mathrm{g} / \mathrm{ml})$ of each of the antibiotics prepared by serial dilution in double strength Mueller Hinton broth. To determine the effects of combining these antibiotics, the same concentrations of each antibiotics used for determining their MICs were combined before the solutions were inoculated with $100 \mu$ l of each of the bacterial strains and incubated at $37^{\circ} \mathrm{C}$ for $24 \mathrm{~h}$. Blank Mueller Hinton broth was used as negative control. The MIC was defined as the lowest dilution that showed no growth in the Mueller Hinton broth.

Checkerboard assay. The interactions between the two antibiotics were determined using the checkerboard as previously described (Petersen et al., 2006). The fractional inhibitory concentration (FIC) was derived from the lowest concentrations of the two antibiotics in combination permitting no visible growth of the test organisms in the Mueller Hinton broth after incubating for $24 \mathrm{~h}$ at $37^{\circ} \mathrm{C}$. FIC indices were calculated using the formula FIC index = (MIC of amoxicillin in combination/ MIC of amoxicillin alone) + (MIC of chloramphenicol in combination/MIC of chloramphenicol alone). In this study, synergy was defined as $\sum$ FIC $\leq 0.5$, additivity as $0.5<\sum$ FIC $\leq 1$, indifference as $1<\sum$ FIC $\leq 4$ and antagonism as $\sum$ FIC $>4$ determined by the checkerboard method according to Petersen and coworkers (2006).

Determination of rate of kill. The Time-kill assay was performed using the broth macrodilution technique (Pankey et al., 2005). The amoxicillin and chlorampheni$\mathrm{col}$ antibiotics were incorporated into $50 \mathrm{ml}$ of Mueller
Hinton broth at $1 /{ }_{2} \mathrm{MIC}$ and MIC respectively. Controls consisting of Mueller Hinton broth with the respective antibiotic added alone at the test concentrations were included in each experiment. The experimental and control flasks were inoculated with each test organism to a final inoculum density of approximately $10^{9} \mathrm{cfu} / \mathrm{ml}$. Immediately after inoculation, aliquots $(100 \mu \mathrm{l})$ of the negative control flasks were taken, serially diluted in sterile distilled water and plated on nutrient agar in order to determine the zero h counts. The test flasks were incubated at $37^{\circ} \mathrm{C}$ with shaking on an orbital shaker at $120 \mathrm{rpm}$. A $100 \mu \mathrm{l}$ aliquot was removed from the culture medium at 0,24 and $48 \mathrm{~h}$ for the determination of $\mathrm{cfu} / \mathrm{ml}$. The problem of antibiotics carryover was addressed by dilution. After incubation, emergent bacterial colonies were enumerated, the mean count $(\mathrm{cfu} / \mathrm{ml})$ for each test and controls was calculated and expressed as $\log _{10}$. The interactions were considered synergistic if there was a decrease of $>2 \log _{10} \mathrm{cfu} / \mathrm{ml}$ in colony counts after $24 \mathrm{~h}$ for the antibiotics combination compared to the activity of each antibiotic used alone. Additivity or indifference was described as a $<2 \log _{10} \mathrm{cfu} / \mathrm{ml}$ change in the average viable counts after $24 \mathrm{~h}$ for the combination, in comparison to the activity of each antibiotic used alone. Antagonism was defined as a $>2 \log _{10} \mathrm{cfu} / \mathrm{ml}$ increase in colony counts after $24 \mathrm{~h}$ for the combination compared to the activity of each antibiotic used alone (Pankey et al., 2005).

Statistical analysis. All the data were subjected to one way analysis of variance (ANOVA) and the mean values were separated at $p<0.05$ using Duncan's Multiple Range Test. The one way ANOVA test was used to determine if there was any statistically significant difference in the size of inhibition zones for each bacterial isolate exposed to each antibiotic alone and the antibiotics combination. All statistical analyses were performed using SPSS software (2009).

\section{RESULTS}

According to our results, amoxicillin, chlorampheni$\mathrm{col}$ and their combinations exhibited significant antibacterial activity as shown in Table 1 . The bacterial inhibition zones produced by amoxicillin ranged between $16.33 \pm 0.58$ and $33.67 \pm 0.58 \mathrm{~mm}$ at the lowest concentration of $62.5 \mu \mathrm{g} / \mathrm{ml}$ while the inhibition zones ranged between $20.33 \pm 0.58$ and $38.33 \pm 0.58 \mathrm{~mm}$ at the highest concentration of $250 \mu \mathrm{g} / \mathrm{ml}$. The inhibition zones produced by chloramphenicol at $62.5 \mu \mathrm{g} / \mathrm{ml}$ ranged from $20.67 \pm 0.58$ to $31.67 \pm 0.58 \mathrm{~mm}$ while those produced at the highest concentration of $250 \mu \mathrm{g} / \mathrm{ml}$ ranged between $27.67 \pm 0.58$ and $37.67 \pm 0.58 \mathrm{~mm}$. Although each antibiotic produced various inhibition zones when used alone, those of their combinations at the lowest concentration of $62.5 \mu \mathrm{g} / \mathrm{ml}$ ranged between $23.67 \pm 0.58$ and $34.67 \pm 0.58 \mathrm{~mm}$. At the highest concentration, $250 \mu \mathrm{g} / \mathrm{ml}$, of the combined amoxicillin and chloramphenicol, the resultant inhibition zones ranged between $31.67 \pm 0.58$ and $39.67 \pm 0.58 \mathrm{~mm}$. Comparatively the inhibition zones produced by the combination of the two antibiotics were mostly wider than those produced when amoxicillin and chloramphenicol were used individually. At the highest concentration for amoxicillin, Proteus vulgaris CSIR 0030 had the least inhibition zone while Shigella sonnei ATCC 29930 had the widest inhibition zone. At the highest concentration of chloramphenicol, Enterococcus cloacae ATCC 13047 had the least inhibition zone while Shigella sonnei ATCC 29930 had the widest inhibi- 
tion zone. For concentration of amoxicillin and chloramphenicol in combination, Staphylococcus aureus ATCC 6538 had the least inhibition zone while Shigella sonnei ATCC 29930 had the widest inhibition zone.

The antibacterial susceptibility testing was further performed by the broth macrodilution method following the recommendations of the Clinical and Laboratory Standard Institute (CLSI, 2009). The MIC breakpoints for the two antibiotics were considered and the susceptibility results were interpreted according to EUCAST (2013). While the MICs of the amoxicillin ranged between 0.488 and $500 \mu \mathrm{g} / \mathrm{ml}$, that of chloramphenicol ranged between 1.953 and $31.25 \mu \mathrm{g} / \mathrm{ml}$. Shigella sonnei ATCC 29930 had the least MIC of $0.488 \mu \mathrm{g} / \mathrm{ml}$ and Salmonella typhi ATCC $13311 \mathrm{had}$ the highest MIC of $500 \mu \mathrm{g} / \mathrm{ml}$ for amoxicillin. While Shigella sonnei ATCC 29930, Psendomonas aeruginosa ATCC 19582 and Klebsiella pneumoniae ATCC 4352 had the least MIC of $1.953 \mu \mathrm{g} / \mathrm{ml}$ for chloramphenicol, the highest MIC of this antibiotic for Proteus vulgaris CSIR 0030, Enterococcus cloacae ATCC 13047, Staphylococcus aureus $\mathrm{OK}_{2 \mathrm{a}}$ and Salmonella typhi ATCC 13311 equaled $7.813 \mu \mathrm{g} /$ ml. A consideration for the MIC breakpoint showed that the isolates were susceptible to chloramphenicol with the exception of Acinetobacter calcoacenticus UP, while they were mostly resistant to amoxicillin with the exception of Shigella sonnei ATCC 29930, Acinetobacter calcoaceuticus UP and Pseudomonas aeruginosa ATCC 19582. The in vitro antibacterial activity of these antibiotics and their combinations was further assessed on the basis of the FIC index representing the sum of the FICs ( FICs) of each antibiotic tested. When the antibacterial combination was considered as synergistic for $\sum F I C \leq 0.5$, additive for $0.5<\sum$ FIC $\leq 1$, indifferent for $1<\sum$ FIC $\leq 4$ and antagonistic for $\sum F I C>4$, the antibacterial combinations showed synergistic interactions $(70.0 \%)$ and additivity/indifference $(30.0 \%)$, whereas antagonism was not recorded in the case of the test organisms. However, while the FICI for the synergistic interaction was between 0.129 and 0.312 , the FICI for the additive interaction was between 0.688 and 1.0 (Table 2).

To validate the synergy detected in the checkerboard antibacterial assay, the time-kill analysis was performed and showed synergistic effects of the antibacterial combinations against all the test isolates. At the $1 / 2$ MIC of the combined antibiotics, no growth was recorded for all the test bacteria except for Klebsiella pneumoniae ATCC 4352, Proteus vulgaris CSIR 0030 and Enterococcus cloacae ATCC 13047 that had their mean $\log \mathrm{cfu} / \mathrm{ml}$ drastically reduced to $2.614 \pm 0.025,2.583 \pm 0.042$ and $3.757 \pm 0.035$ respectively after $24 \mathrm{~h}$ of incubation while the growth of Enterococcus cloacae ATCC 13047 alone was detected after $48 \mathrm{~h}$. At the MIC of the combined antibiotics, no growth was recorded for all the tested bacteria except for Enterococcus cloacae ATCC 13047 alone. However, after $48 \mathrm{~h}$ of incubation all the tubes were sterile (Table 3). The synergy or additivity showed by the combinations of amoxicillin and chloramphenicol in checkerboard analysis was, therefore, affirmed by the degree of synergistic effects exerted on the bacteria as tested by the time-kill analysis.

\section{DISCUSSION}

Multidrug resistance (MDR) is defined as a resistance of an organism to $\geq 3$ antibiotic classes (Lynch \& Zhanel, 2005). In an era with the emergence of multidrug resistant organisms and lack of treatment options for infections with certain microorganisms, bacteria have be-

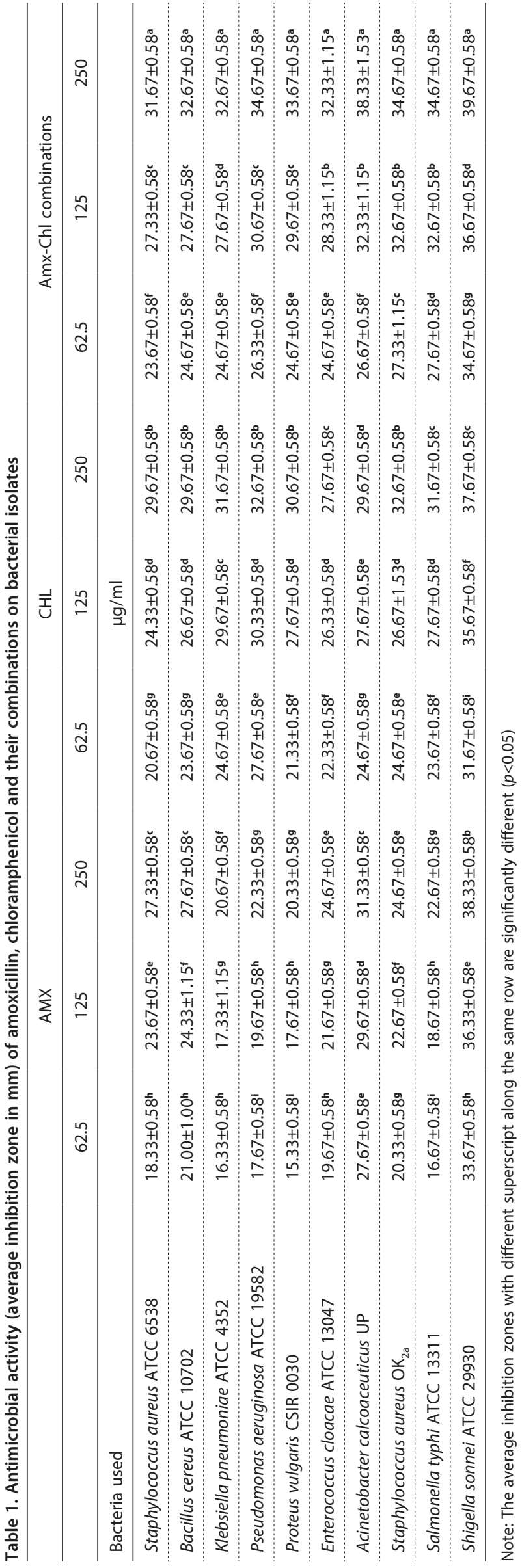


Table 2. MICs and FICs values of amoxicillin, chloramphenicol and their combinations for bacterial isolates

\begin{tabular}{|c|c|c|c|c|c|c|c|}
\hline \multirow[b]{2}{*}{ Bacteria used } & \multicolumn{3}{|c|}{$\operatorname{MICS}(\mu \mathrm{g} / \mathrm{ml})$} & \multicolumn{3}{|c|}{ FICs Indices } & \multirow[b]{2}{*}{ Remarks } \\
\hline & AMX & $\mathrm{CHL}$ & $\mathrm{AMX}-\mathrm{CHL}$ & $\mathrm{FICl} A \mathrm{mx}$ & $\mathrm{FICl} \mathrm{Chl}$ & $\mathrm{FICl}$ & \\
\hline Staphylococcus aureus ATCC 6538 & 3.906 & 3.906 & $1.953 / 1.953$ & 0.5 & 0.5 & 1 & Additive \\
\hline Bacillus cereus ATCC 10702 & 31.25 & 3.906 & $1.953 / 0.976$ & 0.062 & 0.249 & 0.312 & Synergy \\
\hline Klebsiella pneumoniae ATCC 4352 & 3.906 & 1.953 & $0.976 / 0.976$ & 0.249 & 0.499 & 0.748 & Additive \\
\hline Pseudomonas aeruginosa ATCC 19582 & 0.977 & 1.953 & $0.448 / 0.448$ & 0.459 & 0.229 & 0.688 & Additive \\
\hline Proteus vulgaris CSIR 0030 & 250 & 7.818 & $0.976 / 0.976$ & 0.004 & 0.125 & 0.129 & Synergy \\
\hline Enterococcus cloacae ATCC 13047 & 250 & 7.818 & $0.976 / 0.976$ & 0.004 & 0.125 & 0.129 & Synergy \\
\hline Acinetobacter calcoaceuticus UP & 1.953 & 31.25 & $0.448 / 0.448$ & 0.229 & 0.014 & 0.243 & Synergy \\
\hline Staphylococcus aureus $\mathrm{OK}_{2 \mathrm{a}}$ & 125 & 7.818 & $0.976 / 0.976$ & 0.008 & 0.125 & 0.133 & Synergy \\
\hline Salmonella typhi ATCC 13311 & 500 & 7.818 & $0.976 / 0.976$ & 0.002 & 0.125 & 0.127 & Synergy \\
\hline Shigella sonnei ATCC 29930 & 0.488 & 1.953 & $0.06 / 0.06$ & 0.123 & 0.031 & 0.154 & Synergy \\
\hline
\end{tabular}

come resistant to 21 different antibiotics and each isolate is on average resistant to 7-8 antibiotics (D'Costa et al., 2006). In this situation, combination therapy, where two or more antimicrobial agents are used simultaneously, is considered a potentially effective means of minimizing the emergence rate of bacterial resistance. Although there are a large number of antimicrobial agents for medical use and combination of two bactericidal drugs results in synergism, the combination of bactericidal and bacteriostatic agents often results in antagonism (Daschner, 1976) and there will always be a need to discover new agents. Consequently, since drug-drug combinations are convenient models that can give insight into the significance of synergistic and antagonistic interactions of dissimilar drugs (Hall et al., 1983), amoxicillin and chloramphenicol were combined for their potential synergistic effects in view of the increasing resistance rate to these older antibacterial drugs.

In this study, we observed no antagonistic effects on any of the test isolates. The synergistic and additive effects of combining amoxicillin and chloramphenicol against the tested bacteria agree with some studies that demonstrated synergistic interactions between $\beta$-lactams and other therapeutic agents such as clavulanate (Abate
\& Miorner, 1998), ethanbutol (Getahun, 2000), vancomycin (Fox et al., 2006) and aminoglycosides (Güzel \& Gerçeker, 2008). However, while amoxicillin is still being considered a drug of choice within its class because it has better pharmacokinetics than other $\beta$-lactam antibiotics in case of treatment of infections caused by susceptible organisms (Shahhet et al., 2011), chloramphenicol is being used sparingly in human medicine because of its bone marrow toxicity. However, due to the lack of new antibiotics and the global problem of advancing bacterial resistance caused by the indiscriminate use of the current antibiotics (Maviglia et al., 2009), chloramphenicol is being reconsidered as an option for treatment of certain infections in critically ill patients (Nitzan et al., 2010). Despite the potential renaissance of chloramphenicol as an effective antibiotic, there is a dearth of information on its interaction with other antibacterial agents, its coadministration or use in combination therapy.

Although the peptidyl transferase centre is the main target site for many antibiotics and substrate analogs (Spahn \& Prescott, 1996), chloramphenicol binds to the $23 \mathrm{~S}$ rRNA of the $50 \mathrm{~S}$ ribosomal subunit and blocks the elongation of peptides during biosynthesis of proteins (Montero et al., 2007). Chloramphenicol induces oxida-

Table 3. In vitro time-kill activity of Amoxicillin - Chloramphenicol combinations at $1 / 2$ MIC and MIC against bacteria

\begin{tabular}{|c|c|c|c|c|c|c|}
\hline \multirow[b]{3}{*}{ Bacteria used } & \multicolumn{6}{|c|}{ Mean \pm S.D. Dev of Log $\mathrm{cfu} / \mathrm{ml}$ at different concentrations } \\
\hline & \multicolumn{3}{|l|}{$1 / 2 \mathrm{MIC}$} & \multicolumn{3}{|l|}{ MIC } \\
\hline & $\mathrm{Oh}$ & $24 \mathrm{~h}$ & $48 \mathrm{~h}$ & $0 \mathrm{~h}$ & $24 \mathrm{~h}$ & $48 \mathrm{~h}$ \\
\hline Staphylococcus aureus ATCC 6538 & $6.315 \pm 0.024$ & 0 & 0 & $6.145 \pm 0.031$ & 0 & 0 \\
\hline Bacillus cereus ATCC 10702 & $8.685 \pm 0.013$ & 0 & 0 & $8.602 \pm 0.005$ & 0 & 0 \\
\hline Klebsiella pneumoniae ATCC 4352 & $7.902 \pm 0.002$ & $2.614 \pm 0.025$ & 0 & $7.741 \pm 0.076$ & 0 & 0 \\
\hline Pseudomonas aeruginosa ATCC 19582 & $9.677 \pm 0.059$ & 0 & 0 & $9.7627 \pm 0.040$ & 0 & 0 \\
\hline Proteus vulgaris CSIR 0030 & $8.659 \pm 0.035$ & $2.583 \pm 0.042$ & 0 & $8.9165 \pm 0.048$ & 0 & 0 \\
\hline Enterococcus cloacae ATCC 13047 & $8.341 \pm 0.040$ & $3.757 \pm 0.035$ & $2.314 \pm 0.018$ & $8.167 \pm 0.018$ & $1.071 \pm 0.015$ & 0 \\
\hline Acinetobacter calcoaceuticus UP & $7.173 \pm 0.003$ & 0 & 0 & $6.954 \pm 0.010$ & 0 & 0 \\
\hline Staphylococcus aureus $\mathrm{OK}_{2 \mathrm{a}}$ & $6.848 \pm 0.006$ & 0 & 0 & $6.774 \pm 0.005$ & 0 & 0 \\
\hline Salmonella typhi ATCC 13311 & $6.326 \pm 0.022$ & 0 & 0 & $6.395 \pm 0.035$ & 0 & 0 \\
\hline Shigella sonnei ATCC 29930 & $9.644 \pm 0.010$ & 0 & 0 & $9.626 \pm 0.033$ & 0 & 0 \\
\hline
\end{tabular}


tive stress in sensitive bacteria (Aakra et al., 2010), while $\beta$-lactams interfere with the production of peptidoglycan and break the cell of active dividing microorganisms in an iso-osmotic environment (Yellanki et al., 2010). On this basis, the effectiveness of this antibacterial combination may not be overemphasized against resistant bacteria tested in this study. Combining these antibiotics may result in formation of a complex compound having different mechanisms of action and, possibly, acting on different target sites in addition to the target sites for which they were synthesized. Therefore, the synergy of amoxicillin and chloramphenicol may not only, prevent or suppress the emergence of resistant strains but decrease dose-related toxicity and attain a broad spectrum of activity while overcoming both intrinsic and genetic determinants conferring resistance to these antibiotics.

\section{CONCLUSION}

In conclusion, antimicrobial resistance is a significant global problem in the management of patients with infectious diseases. However, combining existing antibiotics may be an alternative means of combating bacterial resistance as the combined agents can exert their different antibacterial activities simultaneously. The lack of antagonism between amoxicillin and chloramphenicol in vitro in checkerboard and time-kill assays suggested that combining these two antibiotics can be an improved therapy in comparison to the use of each antibiotic individually. On the other hand, the observed synergy indicate the potential beneficial value of combining them in the treatment of microbial infections in clinical settings in the era of limited research on new drug development and discovery.

\section{REFERENCES}

Aakra A, Vebø H, Indahl U, Snipen L, Gjerstad $\varnothing$, Lunde M, Nes IF (2010) The response of Enterococcus faecalis V583 to chloramphenicol treatment. Int J Microbiol Article ID 483048. doi: $10.1155 / 2010 / 483048$

Abate A (2000) Anti-tuberculosis activity of $\beta$-lactam antibiotics: prospect for the treatment of MDR tuberculosis. Ethiop J Health Dev 14: 276-296

Abate G, Miorner H (1998) Susceptibility of multi-drug resistant strains of Mycobacterium tuberculosis to amoxicillin in combination with clavulanic acid and ethambutol. I Antimicrob Chemother 42: 735-740

Bou G, Martïnez-Beltran J (2000) Cloning, nucleotide sequencing, and analysis of the gene encoding an AmpC $\beta$-lactamase in Acinetobacter baumannii. Antimicrob Agents Chemother 44: 428-432

Burns JL, Hedi LA, Lien DM (1989) Chloramphenicl resistance in Pseudomonas cepacia because of decreased permeability. Antimicrob Agents Chemother 33: 136-141. doi: 10.1128/AAC.33.2.13

Cameron EAB, Powell KU, Baldwin L, Jones P, Bell GD, Williams SGJ (2004) Helicobacter pylori: antibiotic resistance and eradication rates in Suffolk, UK, 1991-2001. J Med Microbiol 53: 535-538. doi: 10.1099/jmm.0.05499-

Clatworthy AE, Pierson E, Hung DT (2007) Targeting virulence: a new paradigm for antimicrobial therapy. Nat Chem Biol 3: 541-548. doi: $10.1038 /$ nchembio. 2007.2

Clinical and Laboratory Standards Institute (2009) M7-A8, Methods for dilution antimicrobial susceptibility tests for bacteria that grow aerobically; approved standard - 18 th edition. Wayne, PA: CLSI

D'Costa VM, McGrann KM, Hughes DW, Wright GD (2006) Sampling the antibiotic resistome. Sci 311: 374-377. doi: 10.1126/science. 112080

Daniels C, Ramos JL (2009) Adaptive drug resistance mediated by root-nodulation-cell division efflux pumps. Clin Microbiol Infect $\mathbf{1 5}$ (Suppl 1): 32-36. doi: 10.1111/j.1469-0691.2008.02693.x
Das U, Bhattacharya SS (2000) Multidrug resistant Salmonella typhi in Rourkela, Orissa. Indian J Pathol Microbiol 43: 135-138

Daschner FD (1976) Combination of bacteriostatic and bactericidal drugs: lack of significant in vitro antagonism between penicillin, cephalothin and rolitetracycline. Antimicrob Agents Chemother 10: 802808

Edgar R, Friedman N, Molshanski-Mor S, Qimron U (2012) Reversing bacterial resistance to antibiotics by phage-mediated delivery of dominant sensitive genes. Appl Environ Microbiol 78: 744-751. doi: 10.1128/AEM.05741-1

EUCAST (2013) The European Committee on Antimicrobial Susceptibility Testing. Breakpoint tables for interpretation of MICs and zone diameters. Version 3.1, 2013. http://www.eucast.org/clinical_ breakpoints/ (Accessed: 6th November, 2016)

Fox PM, Lampen RJ, Stumpf KS, Archer GL, Climo MW (2006) Successful therapy of experimental endocarditis caused by vancomycinresistant Staphylococcus aureus with a combination of vancomycin and beta-lactam antibiotics. Antimicrob Agents Chemother 50: 2951-2956. doi: 10.1128/AAC.00232-0

Getahun A (2000) Anti-tuberculosis activity of $\beta$-lactam antibiotics: prospect for the treatment of MDR tuberculosis. Ethiop J Health Dev 14: 276-296. http://dx.doi.org/10.4314/ejhd.v14i3.989

Güzel CB, Gerçeker AA (2008) In vitro activities of various antibiotics, alone and in combination with colistin methanesulfonate, against Pseudomonas aeruginosa strains isolated from cystic fibrosis patients. Chemother 54: 147-151. doi: 10.1159/00011974

Hall MJ, Middleton RF, Westmacott D (1983) The fractional inhibitory concentration (FIC) index as a measure of synergy. I Antimicrob Chemother 11: 427-433. doi: 10.1093/jac/11.5.42

Kabra SK (2000) Multidrug-resistant typhoid fever. Trop Doc 30: 599600

Kumar A, Schweizer HP (2005) Bacterial resistance to antibiotics: active efflux and reduced uptake. Adv Drug Deliv Rev 57: 1486-513

Lynch JP 3rd, Zhanel GG (2005) Escalation of antimicrobial resistance among Streptococcus pneumoniae: implications for therapy. Semin Respir Crit Care Med 26: 575-616. doi: 10.1055/s-2005-92552

Maviglia R, Nestorini R, Pennisi M (2009) Role of old antibiotics in multidrug resistant bacterial infections. Curr Drug Targets 10: 895905. doi: $10.2174 / 13894500978910884$

Montero CI, Johnson MR, Chou CJ, Conners SB, Geouge SG, Tachdjian S, Nichols JD, Kelly RM (2007) Response of wild-type and resistant strains of the hyperthermophilic bacterium thermotoga maritime to chloramphenicol challenge. Appl Environ Microbiol 73: 5058-5065. doi: 10.1128/AEM.00453-0

Nitzan O, Suponitzky U, Kennes Y, Chazan B, Raul R, Colodner R (2010) Is chloramphenicol making a comeback? Isr Med Assoc J 12: 371-374

Normark BH, Normark S (2002) Evolution and spread of antibiotic resistance. I Intern Med 252: 91-106. doi: 10.1046/j.13652796.2002.01026.

Pankey G, Ashcraft D, Patel N (2005) In vitro synergy of daptomycin plus rifampin against Enterococcus faecium resistant to both linezolid and vancomycin. Antimicrob Agents Chemother 49: 5166-5168. doi: 10.1128/AAC.49.12.5166-5168.200

Petersen PJ, Labthavikul P, Jones CH, Bradford PA (2006) In vitro antibacterial activities of tigecycline in combination with other antimicrobial agents determined by chequerboard and time-kill kinetic analysis. J Antimicrob Chemother 57: 573-576. doi:10.1093/jac/dki47

Schwartz S, Kehrenberg C, Doublet B, Cloeckaert A (2004) Molecular basis of bacterial resistance to chloramphenicol and florfenicol. FEMS Microbiol Rev 28: 519-542. doi: http://dx.doi.org/10.1016/j. femsre.2004.04.00

Shahhet L, Alraghban D, Chehna D (2011) Improvement of the physicochemical properties of amoxicillin trihydrate powder by recrystallization at different $\mathrm{pH}$ values. Int J Pharm Pharmaceut Sci 3 (Suppl 3): 92-100

Smith E, Williamson M, Wareham N, Kaatz G, Gibbons S (2007) Antibacterial and modulators of bacterial resistance from the immature cones of Chamaecyparis lawsoniana. Phytochem 68: 210-217. doi: 10.1016/j.phytochem.2006.10.00

Spahn CMT, Prescott CD (1996) Throwing a spanner in the works: antibiotics and the translation apparatus. J Mol Med 74: 423-439. doi: $10.1007 / \mathrm{BF} 0021751$

Yellanki SK, Singh J, Ali SJ (2010) Design and characterization of amoxicillin trihydrate mucoadhesive microspheres for prolonged gastric retention. Int J Pharm Sci Drug Res 2: 112-114

Zhang R, Eggleston K, Rotimi V, Zeckhauser RJ (2006) Antibiotic resistance as a global threat: Evidence from China, Kuwait and the United States. Globalization and Health 2: 6. doi: 10.1186/1744-86032- 